\title{
Roland Barthes e a fotografia
}

\section{Roland Barthes and the photography}

\section{Leda Tenório da Motta}

Doutora em Semiologia Literária, pela Université de Paris VII, com pós-doutorado em Linguística; professora do Programa de PósGraduação em Comunicação e Semiótica da Pontifícia Universidade Católica de São Paulo - PUC/SP.

E-mail: Itmotta@pucsp.br

\section{Rodrigo Fontanari}

Doutorando do Programa de Pós-Graduação em Comunicação e Semiótica da Pontifícia Universidade Católica de São Paulo - PUC/ SP; pesquisador-bolsista da Fundação de Amparo à Pesquisa do Estado de São Paulo - Fapesp.

E-mail: rodrigo-fontanari@hotmail.com

\begin{abstract}
Resumo
O presente artigo constitui-se numa resenha e numa pequena exegese de alguns dos mais notáveis textos de comentadores internacionais, notadamente aqueles ainda não traduzidos em língua portuguesa, a consagrar-se ao derradeiro livro de Roland Barthes publicado em vida do autor: $A$ câmara clara. O que aqui se propõe é oferecer subsídios para uma melhor elucidação dessa importante obra que, há 30 anos de seu surgimento, segue pouco estudada, sendo assim desperdiçada sua enorme contribuição às ciências da comunicação e, sobretudo, às reflexões em torno do papel da imagem fotográfica no mundo contemporâneo. Jogou-se com a hipótese de que, sendo um semioclasta, mais que um iconoclasta, Barthes estava em melhor posição para ler e entender imagens.
\end{abstract}

Palavras-chave: Roland Barthes, fotografia, semiótica.

\begin{abstract}
This is a review article and a short exegesis from one of the most important texts of international commentators, especially those not yet translated into Portuguese, that we may consider the last work in Barthes's life, The Camera Lucida. What is proposed here is to offer subsidies to elucidate this important work, which, thirty years after its formation, it hasn't been so much studied, and its huge contribution to science communication got lost, and especially the reflections on the role of photographic image in the contemporary world. It's possible to make some hypothesis that, being a semioclasta, rather than an iconoclast, Barthes was in a better position to read and understand images.
\end{abstract}

Keywords: Roland Barthes, photography, semiotics 


\section{Roland Barthes e a fotografia}

O objetivo desse artigo é apresentar uma resenha e exegese dos principais textos de comentadores internacionais, de difícil acesso, atualmente, no Brasil e, sobretudo, daqueles textos ainda não versados em língua portuguesa que se lançaram na tentativa de compreender essa última obra em vida de Roland Barthes, A câmara clara. Para tanto, elencou-se, como estratégia metodológica, uma pesquisa bibliográfica de amplo espectro.

$\mathrm{Na}$ busca de levantamento do estado da arte a respeito dos escritos sobre fotografia de Roland Barthes, foram encontrados, recentemente, dois textos instigantes, ambos publicados na revista Comunicação \& Linguagem, da Universidade Nova de Lisboa, num dossiê intitulado Fotografia(s): uma abordagem multidisciplinar'. Um deles é A câmara clara: outra pequena história da fotografia, de Geoffrey Batchen, professor da City University New York, um dos maiores especialistas em teoria e historiografia da fotografia. O autor questionou aí as muitas histórias da fotografia de que se dispõe hoje, vendo faltar nelas tudo aquilo que, por outro lado, encontrou em $A$ câmara clara, de Roland Barthes. O último dos escritos barthesianos foi, no seu entender, outra "pequena história da fotografia", digna do importante texto homônimo de Walter Benjamin, escrito em 1931, quase 50 anos antes do livro de Barthes.

Batchen notou que o discurso mais insistente em torno de A câmara clara é que seria a pior coisa que poderia ter acontecido ao discurso fotográfico, uma vez que "parece abandonar o compromisso inicial de Barthes com a análise política das imagens em favor de um hedonismo textual." (BATChAN, 2008: 14). O que Barthes buscava nesse livro era a essência da fotografia ("o que ela era em si mesma"), e a distinguiu das outras comunidades de imagens. Nesse texto, Geoffrey Batchen desenvolveu a concepção de que há uma política sustentada que se desenvolve no curso da escritura de $A$ câmara clara, e que esta política pode ser observada na forma como Barthes lidava com a história. Nesse sentido, para ele, A câmara clara ganharia se fosse lida como uma história da fotografia ou, mesmo, uma história sobre a fotografia, muito mais do que um livro de teoria crítica. Esse ponto de vista levou o autor a criticar a maioria das discussões a respeito de $A$ câmara clara, que tende a focar no par opositivo "studium" e "punctum", e no subtema do livro: a relação da fotografia e da morte. Essas abordagens típicas da obra desviam o olhar da possibilidade de aí encontrar e elaborar uma leitura deste livro com uma pequena história da fotografia.

\footnotetext{
1 Medeiros, Margarida (org.). Fotografia(s): uma abordagem multidisciplinar. Comunicação \& Linguagem, n. 39, Lisboa, janeiro, 2008.
}

Batchen buscou, desde as primeiras páginas de seu artigo, aproximar estruturalmente $A$ câmara clara do ensaio de Benjamin intitulado Pequena história da fotografia, até mesmo ao mostrar que ambos ilustraram a sua história com fotografias relativamente banais; no entanto, estas imagens foram capazes de disparar leituras poéticas, como se também Benjamin procurasse apreender o efeito de "punctum" da sua resposta subjetiva diante de certas imagens. Ainda como sinalizou o autor, embora essas inúmeras correspondências e similitudes com tal texto benjaminiano, Barthes não fez alguma referência a esse texto nem em sua biografia, muito menos em suas notas marginais. Tudo aponta para o fato de que, na edição de 1977 da revista Nouvelle Observateur Photo, da qual Roland Barthes retirou a maioria das fotos que ilustraram $A$ câmara clara, também estava lá uma versão francesa desse célebre ensaio de Walter Benjamin (BATCHEN, 2008: 17).

A história da fotografia em $A$ câmara clara implode o tom objetivo e entrega a uma forma narrativa em primeira pessoa que enuncia experiência do sujeito diante da fotografia e de seu laço traumático com o passado. Barthes escolheu fotografias públicas para falar de algo bem íntimo; do que havia de mais traumático diante dessa imagem ("isso existiu"): descobrir a natureza da experiência fotográfica. A história da fotografia encontrada nessa obra barthesiana deve ser tomada como um modo de leitura em que pouco importam as imagens elencadas, elas são simplesmente pretexto para o texto: escritura da experiência do sujeito diante da imagem. De maneira mais clara, salientou Geoffrey Batchen:

A História continua a ser um lugar poderoso para esse trabalho, como fica evidente na forma como Barthes leva a cabo a representação da sua pequena história da fotografia. Abandonando a narrativa linear e cronológica, as afirmações ilusórias da compreensibilidade, e os valores hierárquicos da maioria dos estudos em fotografia, esta é uma história guiada por uma única pergunta por responder: o que é a fotografia? Ao inserir está ansiedade ontológica no seio da sua narrativa, Barthes não estabelece previamente nenhuma direção para essa narrativa. Ao invés, os leitores são conduzidos numa demanda - com um pouco de ruminação filosófica, um pouco de história social, um pouco de cultura visual, um pouco de romance de detetives - que fala tanto acerca deles próprios (acerca da consciência) como da fotografia (2008: 23).

Barthes pareceu interessado em explorar a possibilidade de inventar uma forma vanguardista de história, e não em fornecer, uma vez mais, uma história das imagens vanguardistas. Em qualquer dos casos, o objetivo do seu livro foi descobrir a natureza da experiência oferecida por 


\section{Roland Barthes e a fotografia}

qualquer fotografia. Em suma, a abordagem histórica demonstrada por $A$ câmara clara produz uma história que é na realidade sobre a fotografia, e não sobre fotografias (BATCHEN, 2008: 22).

Batchen também sustentou a ideia de que a essência da fotografia é a de ser um signo indiciário, o que a distingue de outros sistemas de representação. Como asseverou o mesmo autor: "A noção de Peirce de semiose indixical anula qualquer distinção clara entre um referente e as associações psicológicas a ele aduzidas por um observador." (2008: 19).

Nesse sentido, observando-se o entorno no qual emergiu A câmara clara, ela é uma pequena história da fotografia para Batchen também por ser o um livro que surgiu no final do ano de 1979, quando, então, a fotografia já estava institucionalizada tanto enquanto objeto histórico quanto prática profissional, servindo como último testemunho que "associa intimamente a fotografia à história, e as suas pequenas histórias como a sua própria experiência de fotografias reais, como se o destino de uma dependesse da forma da outra." (2008: 23).

Jean-Claude Milner, em Le pas philosophique de Roland Barthes [Os passos filosóficos de Roland Barthes], parece ter ido de encontro ao pensamento de Batchen a respeito de A câmara clara. Para Jean-Claude, cada palavra, cada alusão, neste livro, deve ser levada a sério. A câmara clara é o momento em que Barthes se soltou do mastro do barco e se entregou ao canto das sereias, metáfora que referenda "O canto da sereia" em O livro por vir, de Maurice Blanchot. Na leitura de Jean-Claude, Barthes acabou por condenar o pensamento de Walter Benjamin: "na esteira de pensamento de Benjamin, a condenação é plena e inteira" (2003: 72). Para esse autor, não há alguma referência clara na qual se possa encontrar apoio para afirmar que Barthes tenha lido o ensaio de Benjamin intitulado Pequena história da fotografia. A única referência a Benjamin - de maneira explícita - apareceu em uma entrevista concedida por Barthes em 1977 e publicada em 1980, em que ele afirmou que, dentre os textos de grande qualidade intelectual que ele notou serem raros, estaria o de Benjamin, porém nada habilita a constatar que ele referendava Pequena história da fotografia ou $A$ obra de arte na era da reprodutibilidade técnica. O seu julgamento a respeito do texto de Benjamin sugeriu que ele era "bom por ser premonitório" (2003: 72), o que faz acreditar que o texto vale-se pela data.

De outro ponto de vista, Barthes inverteu a tese sobre a história que, segundo Benjamin, o anjo da história caminha para trás no futuro, nas vidas por vir, mais do que na morte. E o caminho escolhido por Barthes foi remontar os escombros do passado: "impulsionado pelo progresso, ele contempla os escombros de um passado." (2003 : 72).
Elencando elementos que afastam Benjamin de Barthes, Jean-Claude Milner apontou que Barthes disse não à história - uma invenção moderna tal como a fotografia - para dizer sim à fotografia como arte técnica que congela o tempo, faz do instante algo infinito: reproduz mecanicamente algo que não poderá mais se reproduzir existencialmente. Esse posicionamento barthesiano diante da fotografia vem de encontro ao pensamento de Benjamin desenvolvido em outro ensaio célebre desse autor, intitulado $A$ obra de arte na era da reprodutibilidade técnica, pois, para Barthes, o que se inaugura na era da reprodutibilidade técnica notadamente para o mundo da fotografia - nada altera em relação ao que era considerado como obra de arte até então, visto que "o que se fotografa não deixa de se tornar o que é - único" (2003: 73). O que se fotografa se torna irrepetível, embora reproduzível ao infinito. Para Barthes, a fotografia parece não perder o conceito benjaminiano de "aura", pois ela sempre - por mais reproduzida que a foto venha a ser - será o registro de um instante único. Eis-aí o escândalo barthesiano de $A$ câmara clara.

O outro texto recolhido nesta revista é $A$ fotografia, a modernidade e seu segredo. Antes e depois de Barthes, de Margarida Medeiros, professora do Departamento de Ciência da Comunicação da Universidade Nova de Lisboa, dedica-se a demonstrar, elaborando um fio condutor, a passagem progressista da fotografia que emerge centrada no espanto pela revolução tecnológica do instante congelado de que fala a fotografia, para uma "concepção mais necrófila, que vê na fotografia não o espelho do progresso, mas da dissolução do Ser e que fala insistentemente da fotografia como um dispositivo mortífero." (MedeIROS, 2008: 27). Num certo sentido, a referida autora mostrou que a morte esteve mais ou menos presente na história da fotografia. Nem mesmo autores contemporâneos, tais como Philippe Dubois em $O$ ato fotográfico, não conseguiram retirar a fotografia desse lamaçal da morte. A imagem por excelência que Dubois empregou foi a da relação entre Narciso e Medusa, a Górgona de cabelos em forma de serpente que petrificava de horror quem a ousasse mirar.

Para tanto, Margarida Medeiros elencou um conjunto de textos célebres a respeito da teoria crítica da fotografia para daí recortar o papel da imagem fotográfica na cultura moderna, sinalizando que esses textos não falam simplesmente de uma evidência de pensamento a respeito da fotografia, mas, também, de uma experiência dos traumas vivenciados.

O percurso textual escolhido pela autora parte das primeiras utilizações da fotografia no século XIX, quando então se fotografavam as pessoas em seus leitos de morte. A morte era o vetor da atividade fotográfica: ter um registro dos seus entes queridos antes ou mesmo depois, já mortos. Até mesmo durante o sonho positivista e cientificista naturalista, de fotografar a retina do morto para registrar a 


\section{Roland Barthes e a fotografia}

última imagem vista pelos olhos do mesmo, que foi na década de 1860 e perdurou até o início do século XX. A ideia de morte, ou pelo menos do cadáver, está de certa forma impregnada nos primeiros daguerreótipos em que os retratados permaneciam longos períodos em exposição de maneira rígida, o que Ihes atribuía uma certa face nítida, mas macabra e estranha (mortuária), pois, para ser retratado, era necessário se fazer morto.

A autora apontou, a partir da segunda meta do século XX, um crescente estranhamento do dispositivo fotográfico, que culminou na construção de uma visão tétrica desse aparato técnico de fabricação de imagens. Foram os textos de Susan Sontag, Sobre a fotografia, e de Roland Barthes, $A$ câmara clara, que coroaram uma reflexão apurada para uma interpretação do dispositivo fotográfico como um mecanismo que evoca uma reflexão "sobre a fugacidade da experiência, sobre a morte" (2008: 28) ao acenar claramente a relação com a morte e a prática fotográfica. Barthes considerou talvez a fotografia como uma imagem que produz a morte, enquanto que Sontag discorreu sobre o significado da fotografia na cultura contemporânea, ressaltando os aspectos como o aparelho fotográfico como arma, a prática fotográfica como caçada, remetendo constantemente essa ideia de imagem secular, intimamente relacionada à passagem do tempo e ao "fetichismo da mercadoria". (2008: 39). Nesse sentido, como explicou Miguel Frade quando se pôs a pensar um outro tempo da fotografia - do pioneirismo e do espanto que representava ainda ao olhar o processo para obter uma fotografia:

O que equivale a dizer que os espantos, hoje, são fundamentalmente outros: porque a imagem fotográfica foi-se tornando incapaz, ao longo da sua história de espantar quem quer que seja pela sua simples natureza fotográfica. (...) A imagem fotográfica tornou-se habitual, banal, natural: pensamos saber, ou melhor, esquecemo-nos de que não sabemos exatamente o que ela representa o que ela implica o que ela faz e não faz, e esquecemo-nos, sobretudo, de que ela existe já que, como técnica disponível para gerir as aparências, que por ela se tornam elas mesmas disponíveis, o dispositivo liga-se assim ao domínio da mundaneidade banal (...) (FrADE, 1992: 13).

Essa concepção necrofilizante projetou e amalgamou-se sobre a história da fotografia como se, desde o início, a fotografia tivesse sido concebida como um dispositivo de morte. "Toda a sua história é olhada e envolvida num cenário tétrico, não porque isso seja feito explicitamente, mas porque é visível na forma como a teoria e a história da fotografia se relacionam com o passado desta." (Medeiros, 2008: 33).

Nesse sentido, como bem sinalizou a autora supra, a crítica contemporânea da imagem tem citado incessantemente o texto de Sigmund Freud, Das unheimliche ("O sinistro"), datado de 1919, no qual, para mostrar a ideia de duplicar um objeto, um personagem acena com a possibilidade de negar a finitude em detrimento de assegurar a sua continuidade, assim como seus desdobramentos amplamente experimentados na literatura. Da ideia primitiva da imagem duplicada do "eu", essa cópia fiel que surgiu da projeção do corpo sobre uma superfície qualquer, seja ela o espelho, seja o muro, traz consigo o conceito freudiano de sinistro ou estranho. Pois é a reaparição de algo que por muito tempo era conhecido, mas que, por algum motivo, foi recalcado e que, ao vir à tona, se tornou pavoroso. Esse sentimento, para Freud, deve-se ao retorno do recalcado, que está relacionado, principalmente, à castração, à compulsão pela repetição e a medos ancestrais parcialmente superados.

As investigações freudianas a respeito do conceito de sinistro partiram, de um lado, de uma vertente etimológica, que interessa ao presente artigo particularmente nesse momento, da palavra alemã empregada por Freud para designar o conceito de sinistro - Unheimliche -, vocábulo que encerra os sentidos opostos de algo familiar que é, ao mesmo tempo, vivido com estranheza. E, de outro, uma análise das obras literárias que tematizaram a questão do duplo e que provocam no leitor a sensação de Unheimliche. Tal inquietante estranheza pode ser provocada pela imobilidade de um ser ou vice-versa. Nas palavras de Cesarotto: "quando o inacreditável aparece como real (...) um símbolo assume o lugar e a importância do que é simbolizado, o sinistro vem a lume" (1996: 127).

Como lembrou ainda Cesarotto (cf. 1996), todos os sentidos do indivíduo podem vir a ser atingidos pela sensação de estranheza (Unheimliche). Porém, ele ressaltou que a visão - o campo escópico - é o mais privilegiado dos sentidos corporais a levar esta para acesso a essa questão: a visão possibilita ao sujeito a sensação de certeza (realidade das coisas: aquilo que ele vê realmente existe): "A apreensão do real por meio dos olhos permite ao sujeito posicionar-se perante o mundo externo que, por esta operação, é interiorizada e metabolizada pelo eu." (CESAROTTO, 1996: 134).

O pensamento barthesiano da fotografia parece rebater sobre o de Freud: o que é estranho de grande inquietude (sinistro) parece querer ser negado por meio de um processo de repetição compulsiva que busca a banalização/ normalização, tornando-o "familiar". Toda a concepção barthesiana de fotografia está construída a partir da noção semiótica de índice na medida em que, para ela, a fotografia traz sempre consigo seu referente, numa conexão profunda. Tal é a impregnação dessa concepção indiciária que se atribui a essas imagens técnicas o papel de "almas de um outro mundo" que regressam. O projeto inicial de Barthes de chegar à essência da fotografia fracassou na 


\section{Roland Barthes e a fotografia}

medida em que a foto revela algo que é da ordem do recalcado, aquilo que é demasiadamente obsceno e, por isso, não é verbalizável. Nas palavras de Miguel Frade:

A fotografia é hoje objeto de uma outro mal-estar, também este na civilização, à medida que o seu lugar presente se reconfigura sob a pressão constante de um futuro que começa a eclodir já hoje, como a explosão das imagens que tudo mimam sem que nada se refiram: face ao ( $\mathrm{sic}$ ) que se avizinha, talvez não seja de menor importância assinalar de que modo a fotografia, apesar de poder ser absolutamente irreal, não deixa de exigir uma contacto com a superfície do mundo para se fazer. É nesse sentido que ela pode ser louca, quando o seu realismo absoluto e original começar a surpreender-nos em demasia apenas por poder fazer "regressar à consciência” (...) a própria marca do tempo (1992: 206).

O que se rompe no horizonte da busca de se pensar a fotografia é o caminho possível e interessante para compreender os efeitos comportamentais que a fotografia provoca, quando se esforça a denegação de uma "inquietante estranheza".

Na mesma esteira de leitura psicanalítica de $A$ câmara clara, sobressai Serge Tisseron, psiquiatra, psicanalista e autor de inúmeros livros consagrados à imagem, destacando-se, aqui, Le mystère de la chambre claire: photographie et inconscient [O mistério de a câmara clara: fotografia e inconsciente], obra em que o referido autor fez clara crítica ao livro de Roland Barthes $A$ câmara clara, ao indicar três pontos em que o texto barthesiano sobre a fotografia fracassa sem, no entanto, deixar de ressaltar o tanto que Barthes fez pela fotografia. As ideias de Tisseron parecem mais claras e diretas na parte final do livro, intitulada "Conclusion" ["Conclusão"], em que tal autor colocou a fotografia muito mais próxima da ideia de traço [trace] do que de rastro (pegada) [empreintre], pois este é a marca deixada em profundidade por um corpo pelo contato com uma superfície, enquanto que aquele, o traço, é menos o resultado do contato do que de uma ação física ou química. Para o Dr. Tisseron, pouco importa discutir se o signo fotográfico é mais índice do que ícone; para ele, pouco representa o estatuto semiótico desse signo - interessa-lhe o efeito das relações que os indivíduos estabelecem com a fotografia tanto como consumidores quanto espectadores.

Dessa maneira, Serge Tisseron notou que "ela [a fotografia] não é a exaltação da morte até a representação da vida (...), mas, ao contrário, a exaltação da vida até a representação da morte." (1996: 158).

Ao colocar a fotografia como algo que cativa subjetivamente o espectador, e engajá-la do lado de um pensamento mórbido, ele pareceu deduzir que a imagem faria vincular o seu espectador, sob uma forma atenuada, como a dor de um traumatismo que condenaria o sujeito a um eterno sofrimento ("punctum"). Tal fato, na visão desse autor, não corresponde ao que ensinam os casos clínicos, visto que o psiquismo não rememora passivamente os traumatismos do passado, esperando que o tempo trabalhe para suavizar progressivamente o sofrimento. Ainda sinalizou também o mesmo autor que o "punctum" não é necessariamente algo doloroso, pois "(...) o processo de simbolização nos mostrou que a experiência secreta cuja introspecção se tornou impossível, não é necessariamente dolorosa pode ter sua origem numa experiência feliz." (1996: 161).

Sua segunda crítica se coloca sobre a posição de barthesiana da fotografia, que a situa como "o retorno do morto" por se tratar de uma imagem constituída pelo espectro que advém do sujeito fotografado e também pelo espectador, que descobrem o objeto fotografado como desaparecido para nunca mais. Nesse sentido, Barthes contribuiu para a construção de uma teoria da fotografia como a revelação de um processo melancólico. Para Barthes, essa melancolia da fotografia se deve ao seu caráter indicial, que a coloca no status de imagem sagrada - archeiropoético -, mágica, lou$\mathrm{ca}$, alucinatória intimamente relacionada à morte. Para Tisseron, a fotografia está bem longe dessa ideia corrente de "retorno do morto", mas a tentativa de ultrapassar a ferida aberta da separação primitiva - separação da mãe - que marca o funcionamento psíquico de todo ser humano.

A terceira crítica recai sobre a sentença barthesiana de que "a imagem é da qual estou excluído", pois a fotografia é um conjunto de signos que fazem referências a um passado que se torna, aos espectadores, inacessível. Entretanto, segundo Tisseron, a imagem só exclui aquele que resiste ao seu convite de entrar e se deixar guiar por ela, ou seja, a foto não é senão um esqueleto de signos para aqueles que se recusam em "(...) abandonar sua carne e de explorá-la [a fotografia] como um corpo (1996: 165).

Ainda no pensar psicanalítico da fotografia, deve-se situar o texto de François Soulages, professor na Université de Paris VIII - Institut Nacional d'Histoire d'Arte, intitulado Barthes \& la folie empreinte ou la foi, le scandale et la foi ["Barthes \& rastro da loucura ou da crença, o escândalo e a fé"], por ocasião do colóquio intitulado: "Empreintes de Roland Barthes" ["Rastros de Roland Barthes"], organizado pelo Institut National de l'Audiovisuel - INA em 13 de junho de 2008, em Paris, na Universidade Sorbonne. Nesse texto, o autor debruça-se sobre esse último livro de Roland Barthes, que ele considerou transtornador [bouleversant]. De saída, o autor em tela ainda declarou que $A$ câmara clara é um livro sobre fotografia, e também trata da relação de Barthes com sua mãe e dos últimos dias dela antes de vir a falecer, mas, sobretudo, de um problema tão vivo naquele momen- 


\section{Roland Barthes e a fotografia}

to na vida de Roland Barthes: como viver a morte daqueles que se ama? A fotografia, como sublinhou François Soulages, é um rastro (índice) louco que, em face do seu escândalo - retorno brutal do analógico -, evoca a fé do ser humano. Portanto, a fotografia congela cada um num passado ao qual não se volta mais. Ela guarda em si mesma um elo essencial com o divino que permite - segundo a leitura barthesiana - uma abordagem de fé desse nó que o autor estabeleceu entre fotografia, sofrimento e amor. Na leitura de Soulages, Barthes tomou a fotografia como um "espaço existência edipiano", onde ao filho é permitido reencontrar sua mãe morta, continuar a viver este amor e alcançar, talvez aí, o êxtase: "satori" / "punctum".

No limite, $A$ câmara clara é uma tentativa, a todo custo, do discurso barthesiano de apresentar ao leitor a dificuldade de apreender a essência do sujeito que foi fotografado e da própria fotografia em si. Porém, diante desse êxtase fotográfico que Roland Barthes vivenciou na Foto do Jardim de Inverno de sua mãe com cinco anos de idade, pode-se acreditar que certas fotografias provocam no indivíduo uma experiência de fé, de amor e de loucura. Há, nesse signo barthesiano, uma experiência comprovável, mas não demonstrável, que separa aquele que a pratica daquele que não a vivenciou: imaginário escandaloso e louco que só a fé coloca em que habita o sublime da fotografia. Nesse sentido, o signo fotográfico barthesiano, esse rastro extraordinário do quase sobrenatural, não pode ser compreendido por aquele que nunca amou. As críticas são inúmeras por algumas de suas teses, mas, como bem notou Soulages: “(...) permanece de um valor inestimável, dada a gravidade e a força de algumas interrogações relativas em relação entre o rastro, a fotografia, a mãe, o amor e a morte, relações obrigatoriamente existenciais e edipianas." (2009: 206).

Em outro texto desse colóquio sobre Roland Barthes, intitulado "Incarnations de Roland Barthes" ["Encarnações de Roland Barthes"], de François Gaillard, professor de Filosofia na Universidade de Paris VII, encontra-se que a fotografia seria, para Barthes, um objeto que oferece várias práticas onde se engaja o corpo ou, mesmo, vários corpos: o do fotógrafo, o do espectador e o daquele que foi objeto da fotografia. Para esse autor, "corpo" é uma palavra-maná da obra barthesiana que "marca a presença espectral da fenomenologia em tudo o que Barthes escreveu, de $O$ grau zero da escritura até A câmara clara." (2009: 123).

A semiótica do rastro apresenta uma perturbadora e instigante continuidade: o objeto e o sujeito da enunciação não estão claramente distinguidos. No texto "Le singulier a l'épreuve"2 ["O singular a prova"], de François Wahl, que

2 Texto retirado da revista de crítica contemporânea em fotografia, Cahiers de la photographie, n. 25, Roland Barthes et la photographie: le pire du signe. Paris: Contrejour, 1990. p. 14. foi editor na Seuil, editora em Paris, a qual trouxe a público uma das obras póstumas de Barthes, Incidentes, sublinhouse a admirável maneira pela qual Roland Barthes tomou a fotografia como uma técnica psicoquímica, o que alguns denominam de "rastro" ["empreinte"]. Nesse tipo de registro, a interpretação somente poderia ser esmagada, reduzida a um puro reconhecimento do "é isso". No entanto, não se quer afirmar que Barthes ignorou as intervenções do homem sobre a fotografia (enquadramento, distância, luz, turvo, giro etc.), mas, como declarou Jean Arrouye, professor na Universidade d'Aix-en-Provence, em texto dedicado A câmara clara, "Narrativité photographiques ou l'animadversion de Barthes"3 ["Narratividade fotográfica ou a antipatia de Barthes"], o que parece é que todas essas intervenções pertencem ao plano da conotação, a um código cultural de representação ou da disposição do vidro da janela que não muda fundamentalmente a natureza do espetáculo observado e representado pela fotografia. A característica particular da fotografia - no seu estado literal e em razão da sua natureza absolutamente analógica é a de constituir uma mensagem sem código. É no nível da coisa percebida, do espetáculo mostrado - plano da denotação - que se constrói e se manifesta o sentido da fotografia, e é nessa mesma instância que se apresenta sua capacidade de fazer história.

Essa semiótica ou semiologia do rastro está intimamente associada à semiologia segunda que Émile Benveniste delineou: sentir o formigamento da língua, perceber o quanto o sistema (paradigma) está inscrito no próprio corpo daquele que vive naquela língua.

Gabriel Bauret, fotógrafo que teve sua tese dirigida por Roland Barthes, em seu texto a respeito de $A$ câmara clara intitulado 'L'esquisse d'une théorie a la denière aventure d'une pensée"4 ["O esboço de uma teoria a última aventura de um pensamento"], notou que, se em A mensagem fotográfica - texto que se inscreve no contexto de Elementos de semiologia e que deve ser lido na mesma perspectiva de Mitologias - Roland Barthes visionava uma possível teoria da fotografia, $A$ câmara clara se situa à margem de toda essa busca, ao menos à primeira vista, pois a famosa e instigante distinção que ele operou entre "punctum" e "studium" poderia ser considerada uma teoria sutil da fotografia. No entanto, não constitui a mais interessante das teorias, jamais visando a respeito dessa arte. Este livro é o mais paradoxal dos textos a respeito de fotografia. Para Bauret, pode-se "considerá-lo mais autobiográfico de Barthes, mas, talvez, também o mais filosófico." (1990: 12). O discurso construído por Barthes é o mais exterior, o mais

\footnotetext{
${ }^{3}$ Idem., p. 40.

${ }^{4}$ Idem., p. 07.
} 


\section{Roland Barthes e a fotografia}

estranho à história, à técnica e a todas as teorias elaboradas até o momento; entretanto, não deixa de se constituir num dos mais pertinentes olhares sobre a fotografia. Nesse último texto, inteiramente consagrado à fotografia, o olhar barthesiano é de uma lucidez com que ele mesmo se assustou; Barthes refutou aí a teoria, como também a foto artística, pois é de certa forma uma imagem particular, singular, como uma presença evidente, e sua circulação que foram postas em causa.

Daniel Bougnoux, filósofo e professor emérito da Universidade de Stendhal, de Grenoble, em seu texto de abertura do colóquio "Les empreintes de Roland Barthes" ["Os rastros de Roland Barthes"], intitulado "Les empreintes, non l'emprise" ["Os rastros, não a influência"], notou que, desde 1968, com o texto "O efeito de real", bem como com a fotografia, a música e, mesmo, com certa poesia (haicai), Barthes iniciou sua exploração de uma semiótica inferior a do índice -, que privilegia um signo não codificado, uma fenda obscura entre a presença real e a representação. Para Bougnoux, o "punctum" fotográfico barthesiano, a aura benjaminiana, são brechas filosóficas e semióticas para ir mais próximo do real: menos influência, mais presença no mundo e mais distância. O caminho é dissociar o real de realidade. Nessa fenda, se situam Roland Barthes e Rosalind Krauss, que foram, talvez, os únicos a colocar a fotografia num justo ponto de vista: o da relação com o real. Lacan distinguiu a realidade de tudo o que existe, o real. A realidade seria tudo que fosse perceptível, acessível, entendível pelo ser humano, enquanto que o real seria o conjunto das coisas, independentemente de ser percebido pelos seres humanos. Refere-se ao que é autêntico; inalterável verdade simultaneamente - um ser e a dimensão externa da experiência. É o que a linguagem (simbólico) não pode e não consegue tocar - o impossível -, impenetrável pelo sujeito para quem a realidade tem uma natureza fantasmática.

Diante dessas várias maneiras de denominar tal apagamento da linguagem - o "punctum" (êxtase fotográfico), o haicai ou, até mesmo, a efervescência amorosa -, o sujeito experimenta "(...) um engajamento face ao (sic) objeto num indivisível, numa irrefutável imanência que é a sentença de morte do ego transcendental". Há, aí, o desejo de possuir e, ao mesmo tempo, de ser possuído: um jogo linguístico em que o discurso ou o sentido não pega. A sensação do "punctum" fotográfico não constitui a experiência de um sujeito em face de uma imagem, mas aquela recebida do mundo a partir de uma invasão de um transe discreto que o deixa "cerrado-possuído-paralisado" ["poigné-saisi-transi"]. Essa mesma experiência ocorre, segundo Bougnoux, com a efervescência amorosa e com o haicai. Enfim, remarcou ainda o autor que o "punctum" é a inversão do possuir, é o desprendimento [(dé) saisissement] do sujeito sensível, e o apagamento do "studium", ou melhor, de qualquer tentativa e desejo de empreendimento retórico.

Consoante esse entendimento, a rastro do "punctum", para Daniel Bougnoux, parece se deslocar do sentido da visão para o tátil. Esse deslocamento não quer dizer muito, a não ser um maior arrebatamento do sujeito sobre ele mesmo. Essas impressões, esses rastros amalgamam ainda mais o "não-querer-possuir", e a sua passividade leva a uma atenuação da arrogância e da inevitável violência das várias enunciações do sujeito. Fica-se cada vez mais próximo do desejo de Neutro. "Não-querer-possuir", como revelou pensar Éric Marty, editor das Oeuvres complèts de Roland Barthes e professor de literatura na Universidade de Paris VII, em seu livro Roland Barthes: o ofício de escrever, é essa queda fora da linguagem que, por sua vez, estaria próxima do sentido do Neutro que, em uma das suas acepções, poderia ser entendido como a falta de linguagem, uma forma de silêncio, de apagamento, de suspensão do sujeito. O "não-querer-possuir" é o êxtase eternamente suspenso em um puro presente.

No texto "Du signe à la trace" [ "Do signo ao traço"], de Louise Merzeau, conferencista em ciências da informação e da comunicação, e membro do laboratório CrisCentro de Recherche en Information Spécialisée et Médiation des Savoirs, desse mesmo colóquio em homenagem a Barthes, apontou-se que tais rastros para esse autor podem assumir várias formas e ter vários nomes, segundo o contexto e o objeto evocado: "satori", "picada", "detalhe" e "punctum", dentre outros. São termos que não podem ser teorizados, pois deslocam o texto crítico de toda a teoria para conduzi-lo mais próximo da escritura, de uma escritura-traço. Como notou Merzeau, o texto é "descrito como um corpo marcado de afetos." (2009: 127). A obra barthesiana é marcada por essa escritura sintomática em que o discurso perde a segurança de tudo saber. Para Merzeau, é na fotografia que o texto-traço volta próximo de seu modelo e sua lógica: "ela [fotografia] reconstrói a mesma lógica indicial que separa o discurso de sua interpretação." (2009: 131).

Nesses últimos escritos sobre fotografia, Barthes não a encarou mais como signo analógico, mas como um traço, uma emanação luminosa, uma carne onde qualquer coisa do corpo que se sedimenta, uma pele a dividir.

Merzeau sublinhou que Barthes lidava com o que havia de mais evidente de sentido na fotografia: "na fotografia, eu não posso jamais negar que a coisa esteve lá." (2009: 131). Para esse autor, não se pode encarar A câmara clara como uma semiótica; nesse livro, Barthes se entregou à coalescência do signo para produzir um discurso fenomenológico que não cede à analogia do signo, fazen- 


\section{Roland Barthes e a fotografia}

do desse livro não uma questão específica de índice, mas de um traço do "isso existiu" ["ça-a-été"].

Daniel Bougnoux sinalizou um importante passo no horizonte da escritura de A câmara clara: a de a obra ter servido como vestígio investigativo para um campo de pesquisa denominado mediologia, campo teórico que traz a lume os efeitos simbólicos das inovações tecnológicas. Assim, separando conteúdo da forma, a maneira de analisar a imagem fotográfica introduzida pelo rastro, tal qual empregada por Barthes em seu derradeiro livro, não tem nenhuma relação com a mensagem, mas com o meio, com a forma. É o que justifica a substituição "(...) da economia da mensagem por uma economia do media e a semiologia por uma mediologia." (2009: 141).

Todos os comentadores de A câmara clara sublinharam essa busca fenomenológica pela essência da fotografia saber a todo custo o que ela, em si mesma, passa, por sua vez, pela insistência barthesiana sobre o aspecto material e químico da fotografia, pois ela é a prova "é isso" ["c'est ça"] de que "isso existiu" ["ça-a-été"]. Essa é a noema da fotografia, ou seja, aquilo que é percebido, apreendido do objeto da percepção. A fotografia tomada por Barthes como fenômeno de consciência: é a coisa em sua essência que importa. Barthes pôde, na fotografia, reencontrar sua mãe - sua realidade, seu passado - porque a foto é uma emanação do referente, um rastro, um traço dela. O efeito que esse traço, essa emanação produz não é de restituir o que foi abolido pelo tempo, pela distância, mas uma atestação de que aquilo que se vê existiu / aconteceu. A fotografia com testemunho de fé que atesta a ressurreição e proclama essa boa nova. Tais são a demonstração e o testemunho de fé encontrados na foto, que levaram Barthes a compará-la ao santo sudário.

A questão que fica para cada um é a seguinte: como lidar com essa virada teórico-conceitual instaurada pelo "punctum" no campo das imagens? Pode-se, de saída, dizer que não tem nada a ver com a concepção de "memória involuntária", tão explorada na obra proustiana Em busca do tempo perdido. Para o último Barthes de $A$ câmara clara, não há nada de memória na foto pungente; o que ela provoca é uma atestação de que aquilo que se registrou sobre a chapa metálica realmente aconteceu, "estava lá". De resto, basta saber o quanto Barthes se referiu a Proust e o quanto Proust esteve presente em seus momentos finais, sendo um tema recorrente nas derradeiras aulas no Collège de France, talvez o que induziu os comentadores de A câmara clara a pensarem que o "punctum" é o que há de mais proustiano nesse Barthes, apontando apressada e erroneamente que Barthes se contradisse, pois, no fragmento 28 , ele destacou que:
Por uma vez, a fotografia me dava um sentimento tão seguro quanto a lembrança, tal como a experimentou Proust, quando, ao abaixar-se certo dia para descalçar-se, percebeu bruscamente em sua memória a face de sua avó verdadeira, "cuja realidade viva pela primeira vez eu encontrava em uma lembrança involuntária e completa" (OCV, 2002: 845).

Enquanto que, no fragmento 35, logo na abertura, o autor colocou: "A fotografia não rememora o passado (não há nada de proustiano em uma foto)." (OCV, 2002: 855). É preciso esclarecer o fato. Barthes não afirmou que a foto tem algo de (re) memória proustiana; ele simplesmente aproximou a ideia para comparar e ainda remarcar bem que a foto lhe dava "(...) um sentimento tão seguro quanto a lembrança, tal como a experimentou Proust (...)". Portanto, não há contradição alguma quando, novamente, recorreu a Proust para negá-lo, "(não há nada de proustiano em uma foto)", pois, para Roland Barthes, a foto não rememorava nada.

A fotografia está antropologicamente ligada à morte pelo seu poder de imobilizar o tempo e a interpretação, o que faz com que aquele evento registrado perpetue num movimento de eterno retorno, excluindo qualquer possibilidade de catarse. Essa visão filosófica séria a respeito da fotografia levou Barthes a afirmar, bem na abertura do fragmento 38, que:

Todos esses jovens fotógrafos que se movimentam no mundo, dedicando-se à captura da atualidade, não sabem que são agentes da Morte. É o modo como nosso tempo assume a Morte: sob o álibi denegador do perdidamente vivo, de que o fotógrafo é de algum modo o profissional (OCV, 2002: 865).

O estatuto semiótico da fotografia se situa para além da forma estabelecida pela representação: a foto coloca o sujeito diante de uma individualidade sem código, sem máscara, até mesmo sem mediação. A verdadeira ferida da fotografia está no seu curto-circuito temporal: tornar o passado presente; no entanto, esse passado é agora presente como morto. Enfim, a fotografia consolida o sonho barthesiano de escritura branca, estatuto que a linguagem só pode sonhar em tangenciar. A neutralidade do signo constitui a característica essencial desse regime de representação. Porém, essa neutralidade que está na essência da fotografia parece ser abafada, fazendo com que se esqueça de que se trata de uma analogia do retorno brutal para se passar como uma analogia do efeito natural (arte). 


\section{Roland Barthes e a fotografia}

\section{Referências}

BARTHES, Roland. Oeuvres complètes $-5 T$. Nouvelle édition revue, corrigée et présentée par Éric Marty. Paris: Seuil, 2002.

Benjamin, Walter. Obras escolhidas: magia e técnica, arte e política. São Paulo: Brasiliense, 1994.

Benveniste, Émile. Problemas de linguística geral II. Campinas: Pontes, 1989.

Bougnoux, Daniel (org.). Empreintes de Roland Barthes. Actes du colloque organisé par l'INA sous la direction de Daniel Bougnoux. Nantes: C. Defaut / INA, 2009.

Cesarotto, Oscar. No olho do outro: o homem de areia segundo Hoffman, Freud e Gaiman. São Paulo: lluminuras, 1996.

Duboıs, Philippe. O ato fotográfico. Campinas: Papirus, 1994.

Frade, Pedro Miguel. Figuras do espanto: a fotografia antes da sua cultura. Coimbra: ASA, 1998.
Klein, William; Boudinet, Michel; Delaborde, Michel; Bauret, Jean-François; Gardner, Alexander \& Michals, Duane. Roland Barthes et la photographie: le pire des signes. Cahiers de la photographie, n. 25, Paris, Contrejours, 1990. Krauss, Rosalind. Le photographique. Paris: Macula, 1992 LAsowskI, Aliocha Wald (coord.). Dossier: Barthes refait signe. Le Magazine Littéraire, n. 482, Janvier, 2009.

MARTY, Éric. Roland Barthes: o ofício de escrever. São Paulo: Bertrand Brasil, 2009.

Medeiros, Margarida (org.). Fotografia(s): uma abordagem multidisciplinar. Comunicação \& Linguagem, n. 39, Lisboa, janeiro, 2008.

Miller, Jacque-Alain. Percurso de Lacan: uma introdução. Rio de Janeiro: Jorge Zahar, 1987.

MotTA, Leda Tenório da. Proust: a violência sutil do riso. São Paulo: Perspectiva, 2007.

TISSERION, Serge. Le mystère de la chambre claire. Paris: Flammarion, 1999. 